\title{
Las Células TC-1 Implantadas Invaden a las Fibras Muscula- res Esqueléticas Adyacentes en un Modelo Murino de Cáncer
}

\author{
Implanted TC-1 Cells Invade Neighboring Skeletal Muscle Fibers in a Cancer Murine Model
}

\author{
Adolfo Soto-Domínguez*; Javier I. Vázquez-Morales*; Víktor J. Romero-Díaz*; \\ Martha E. Santoyo-Pérez** \& Julio Sepúlveda-Saavedra*
}

SOTO-DOMÍNGUEZ, A.; VÁZQUEZ-MORALES, J. I; ROMERO-DÍAZ, V. J.; SANTOYO-PÉREZ, M. E. \& SEPÚLVEDASAAVEDRA, J. Las células TC-1 implantadas invaden a las fibras musculares esqueléticas adyacentes en un modelo murino de cáncer. Int. J. Morphol., 31(2):520-527, 2013.

RESUMEN: La línea celular TC-1 se ha utilizado en la evaluación de la inmunoterapia antitumoral. No existen reportes sobre el efecto de las células TC-1 en tejidos adyacentes cuando se implantan en ratones C57BL/6. El objetivo de este trabajo fue evaluar la interacción entre las células TC-1 implantadas y las fibras musculares adyacentes. Se emplearon 8 ratones con células TC1 implantadas y 3 ratones sin células. Se colectó el sitio del implante de las células tumorales a 10 días, las muestras se procesaron para microscopia de luz y electrónica de transmisión. Se realizaron tinciones con HyE y tricrómico de Masson, histoquímica con PAS, e inmunohistoquímica para identificar citoqueratinas, actina específica de músculo y metaloproteinasa de la matriz-9 (MMP-9). También se comparó el diámetro de las fibras musculares en ambos grupos de estudio. En el análisis histológico se observaron masas de células TC-1 que infiltran el tejido muscular y separan a las fibras entre sí. Las fibras musculares mostraron variaciones en la intensidad de la tinción y disminución de su diámetro. Se observaron masas de células tumorales TC-1 que invaden la fibra hacia el interior y logran atravesar la lámina externa y el sarcolema que las rodea. Se observó positividad a MMP-9 en el citoplasma de las células TC-1, y en el espacio entre las células tumorales y las fibras musculares. En el análisis ultraestructural se observó fragmentación y variaciones en el grosor de la lámina externa y vesículas subsarcolemales en el sitio en donde las células TC-1 invaden las fibras.Ahí, las células TC1 emiten proyecciones de membrana similares a pseudópodos. Existió diferencia estadística significativa en el diámetro de las fibras del grupo experimental vs el grupo control. Estos hallazgos deben tomarse en cuenta cuando se utiliza este modelo murino de cáncer para valorar la respuesta de inmunoterapia antitumoral.

PALABRAS CLAVE: Células TC-1; Invasión intrasarcoplásmica; Modelo murino de cáncer.

\section{INTRODUCCIÓN}

Los pacientes afectados de enfermedad neoplásica maligna cursan con caquexia severa, atribuible principalmente a una atrofia importante y progresiva de la masa muscular corporal (Argilés et al., 2006). A la fecha, la invasión de células cancerosas al interior de las fibras musculares esqueléticas ha sido reportada con poca frecuencia (Sridhar et al., 1987; Ueyama et al., 1998; Mathis et al., 2010), y en la práctica clínica han sido raramente reportados los casos de tumores metastásicos desarrollados en músculo (Luo et al., 2002). Cuando se presentan, las metástasis a músculo esquelético se han asociado con un mal pronóstico, que se traduce en una menor esperanza de vida para el paciente (Ferrandina et al., 2006; Albiruni et al., 2007; Mathis et al.).
Tanto en modelos animales experimentales como en reportes histopatológicos de pacientes, se han descrito tres formas histológicas de interacción de las células cancerosas con las fibras musculares esqueléticas: 1) Infiltración (Brandes et al., 1967; Gabbert et al., 1987; Lamura et al., 2003). 2) Interacción transcelular, reportada por Babaï (1976), y 3) Invasión intrasarcoplásmica, es la interacción más rara y con peor pronóstico en pacientes que la presentaron, se caracteriza por la invasión de las células cancerosas al interior de las fibras del músculo esquelético, con la aparición de agregados de células tumorales en el sarcoplasma (Carr et al., 1976; Slatkin \& Pearson, 1976; Stratton et al., 1982).

\footnotetext{
* Departamento de Histología, Facultad de Medicina, Universidad Autónoma de Nuevo León, Monterrey, N.L., México.

*** Departamento de Ciencias Morfológicas, Facultad de Medicina, Universidad Autónoma de San Luis Potosí, San Luis Potosí, México.
} 
La línea celular tumoral TC-1 se desarrolló por Lin et al. (1996) a partir de un cultivo primario de células epiteliales de pulmón de ratón C57BL/6, se co-transformaron para expresar las proteínas E6 y E7 del virus del papiloma humano tipo 16 (HPV-16), y el oncogén c-Haras. Cuando son implantadas en la cepa C57BL/6 no producen rechazo inmunológico, dado que a partir de esa cepa se originaron. Las células tumorales TC-1, se han utilizado extensamente como modelo de cáncer en la evaluación de la eficacia de inmunoterapia contra tumores inducidos por HPV, cuyas células expresan en su membrana antígenos virales (Smahel et al., 2003; Tuve et al., 2007; Kang et al., 2012). Sin embargo, a la fecha, no se han reportado los cambios morfológicos que esta línea celular ocasiona en los tejidos adyacentes, como es el tejido muscular al ser implantada en un modelo murino de cáncer.

\section{MATERIAL Y MÉTODO}

Línea celular tumoral TC-1 y técnicas de cultivo e implante celular. La línea celular TC-1 se obtuvo de la ATCC (CRL-2785) (Manassas, VA, USA). Las células se cultivaron en medio de Dulbecco modificado por Eagle, suplementado con suero bovino fetal $10 \%$ y se incubaron a $37^{\circ} \mathrm{C}$ en una atmósfera de $5 \% \mathrm{CO} 2$ y $95 \%$ de humedad. Al observar la monocapa en confluencia, las células se cosecharon añadiendo $1 \mathrm{~mL}$ de tripsina $0,25 \%$. Posteriormente la suspensión celular se mantuvo en hielo, se lavó con solución buffer de fosfatos (PBS) pH 7,2-7,4 tres veces, y se ajustó a una concentración de $5 \times 10^{4}$ células en $100 \mathrm{~mL}$ de PBS.

Esta concentración celular se implantó por vía subcutánea en la extremidad posterior derecha de 8 ratones C57BL/6 (grupo experimental), de 5-6 semanas de edad y peso entre 25 a $30 \mathrm{~g}$. Antes y después de realizar el implante se analizó la viabilidad de la suspensión celular $\geq 95 \%$ con una mezcla 1:1 con azul de tripano. Otro grupo de ratones sin células TC-1 implantadas se consideró como grupo control $(n=3)$. Los ratones se mantuvieron con una dieta estándar de laboratorio con agua ad libitum, ciclos de luz y oscuridad de 12 horas en el bioterio del Departamento de Histología, Facultad de Medicina, UANL.

Colecta de tejidos. En este estudio se evaluaron los cambios morfológicos tempranos. El día del implante de las células tumorales se consideró como día 0 . A los 10 días post-implante los ratones de cada grupo se sacrificaron por dislocación cervical y se perfundieron por punción en el ventrículo izquierdo con glutaraldehído $0,25 \%$ en buffer de cacodilatos pH 7,2-7,4. Posteriormente se obtuvo el sitio del implante de las células tumorales, ya que en este tiempo aun no es posible observar una masa tumoral. Las muestras se dividieron para su procesamiento para microscopia de luz o electrónica de transmisión.

Evaluación histológica. Una parte de la muestra se fijó por inmersión en una solución de paraformaldehído $4 \%$ disuelto en PBS, se procesó por la técnica histológica hasta incluirla en parafina. A partir de los bloques se obtuvieron cortes histológicos de 5 micras que se tiñeron con $\mathrm{H}$ E, o con el método tricrómico de Masson para realizar la evaluación histológica.

Evaluación Histoquímica. Para la evaluación histoquímica de la lámina externa de las fibras musculares y la matriz extracelular, se obtuvieron cortes de 5 micras que se analizaron con el método del Ácido Peryódico de Schiff (PAS) con y sin diastasa, para distinguir entre el glucógeno y los polisacáridos complejos de la lámina externa.

Evaluación Inmunohistoquímica. Para el análisis inmunohistoquímico se obtuvieron cortes de 4 micras, y se utilizaron anticuerpos monoclonales específicos anticitoqueratinas AE1/AE3 (dilución 1:100) para identificar a las células TC-1 por su origen epitelial, y anti-actina específica de músculo (dilución 1:100) para identificar a las fibras musculares. Para identificar a la metaloproteinasa de la matriz-9 se utilizaron anticuerpos específicos (dilución 1:400). Como sistema de detección se utilizó el sistema Envision ${ }^{\circledR}$ (los anticuerpos y el sistema de detección se adquirieron de Dako Cytomation inc $($ )). Como revelador se utilizó 3,3'diaminobencidina (DAB). Los núcleos se contrastaron con hematoxilina. Para los controles de técnica se emplearon cortes histológicos de órganos testigos positivos de tonsila palatina, lengua y yeyuno respectivamente, como control negativo se omitió la incubación con el anticuerpo monoclonal. Las muestras se analizaron a microscopia de luz.

Análisis morfométrico. En el análisis morfométrico se observaron los cortes teñidos con el método tricrómico de Masson. Se identificaron las fibras musculares en corte transversal. Posteriormente, se realizó un muestreo aleatorio, y se midieron los diámetros y áreas de las secciones transversales de 200 fibras musculares en cada ratón con ayuda del analizador de imagen y el software NIS elements versión 2.30 .

Los resultados obtenidos se expresaron en micras cuadradas, a partir de estos datos se obtuvo la media y desviación estándar de cada muestra. Los resultados del grupo experimental se contrastaron con los del grupo con- 
SOTO-DOMÍNGUEZ, A.; VÁZQUEZ-MORALES, J. I; ROMERO-DÍAZ, V. J.; SANTOYO-PÉREZ, M. E. \& SEPÚLVEDA-SAAVEDRA, J. Las células TC-1 implantadas invaden a las fibras musculares esqueléticas adyacentes en un modelo murino de cáncer. Int. J. Morphol., 31(2):520-527, 2013.

trol por una prueba de medias pareadas con el software SPSS 15.0.

Evaluación ultraestructural. Otra parte de la muestra obtenida del sitio del implante, se fijó por inmersión en solución fijadora de Karnovsky-Ito (paraformaldehído 4\%, glutaraldehído $5 \%$, y ácido pícrico $0.05 \%$ en PBS $0.1 \mathrm{M}$ ) (Ito $\&$ Karnowsky, 1968). Después de una hora en fijador las muestras se lavaron brevemente con PBS y se postfijaron en tetraóxido de osmio acuoso $2 \%$ por 1 hora a temperatura ambiente. En seguida el tejido se trató con solución acuosa de nitrato de uranilo $1 \%$ y se deshidrató con etanol. Finalmente las muestras se embebieron en resinas epóxicas y se formaron bloques de acuerdo con la técnica de Luft (1961). De los bloques se obtuvieron mediante ultramicrotomía cortes semifinos que se tiñeron con azul de toluidina $1 \%$ y se analizaron en el microscopio óptico; así como cortes ultrafinos que se montaron en rejillas de cobre de 200 mesh sin medio de soporte y se contrastaron con acetato de uranilo (Watson, 1958) seguido de citrato de plomo (Venable \& Coggeshall, 1965). Las muestras se analizaron en un microscopio electrónico de transmisión Carl Zeiss EM109.

\section{RESULTADOS}

Evaluación histológica. A 10 días post-implante no se observó ninguna tumoración. En el análisis histológico del sitio del implante de las células tumorales, se observaron masas de células TC-1, algunas de las cuales infiltran el tejido muscular separando las fibras musculares entre sí. Destacó la disminución del diámetro de las fibras musculares en el sitio en que las células tumorales infiltran al tejido muscular. También se observaron variaciones en la intensidad de la tinción de las fibras musculares (Fig. 1A).

Un hallazgo importante en nuestro estudio, fue que se observaron fibras musculares con grandes masas de células tumorales TC-1 que invaden a la fibra y se sitúan en el sarcoplasma (Fig. 1B).

Por otra parte, también se observó un cambio en el patrón de tinción de las fibras musculares, que se tiñeron de azul en lugar del rojo brillante característico de las células del músculo esquelético teñidas con el método tricrómico de Masson (Fig. 1C).

Evaluación histoquímica. Al analizar las muestras con el método de PAS con diastasa, se observaron fibras musculares con pérdida de la continuidad de la lámina externa que las rodea en el sitio en que fueron invadidas por las células tumorales, que además mostraron positividad en su citoplasma (Fig. 1D). En el espacio extracelular se observaron también células tumorales con positividad, así como material PAS positivo resistente a la diastasa entre las fibras musculares sin presencia de células tumorales (Fig. 1D).

Evaluación inmunohistoquímica. En el análisis inmunohistoquímico con anticuerpos monoclonales específicos anti-citoqueratinas AE1/AE3 y anti-actina específica de músculo se corroboró la presencia de las células tumorales que infiltran a las fibras musculares. También se identificaron las masas de células TC-1 positivas para citoqueratinas en el interior del sarcoplasma de las fibras musculares.

Otro hallazgo en este estudio fue que se observó positividad a la MMP-9 tanto en el citoplasma de las células tumorales como en el espacio entre las células tumorales y el músculo estriado (Fig. 1E).

Análisis morfométrico. En el análisis morfométrico, se corroboró la disminución del diámetro de las fibras musculares observada en el análisis histológico del sitio del implante de las células tumorales. Al contrastar los resultados del grupo experimental vs el grupo control se observó una diferencia estadística significativa para un valor de $\mathrm{p} \leq 0,05$ (Fig. 1F).

Evaluación ultraestructural. En el análisis a microscopia electrónica de transmisión se observó que las células TC1 infiltran a las fibras musculares, que mostraron signos ultraestructurales de atrofia, destrucción y separación de los miofilamentos, así como variación en la electrodensidad de las miofibrillas (Fig. 2A).

Por otra parte, las células tumorales presentaron un núcleo grande, eucromático, con nucléolo prominente y poco citoplasma con escasos organelos. Otra característica de las células TC-1 fue la presencia de signos ultraestructurales propios de la migración celular: núcleos alargados y constreñidos en la parte central, así como múltiples proyecciones de la membrana en forma de pseudópodos, que se presentan en las áreas en donde la lámina externa de las fibras musculares muestra variaciones en el grosor y fragmentación (Figs. 2B y C).

Además de la destrucción de la lámina externa, también se observó ruptura del sarcolema y la presencia de pequeñas vesículas subsarcolemales asociadas a los sitios de fragmentación del sarcolema (Fig. 2D). La presencia de células tumorales que invaden al interior de las fibras musculares se confirmó en el análisis ultraestructural. 

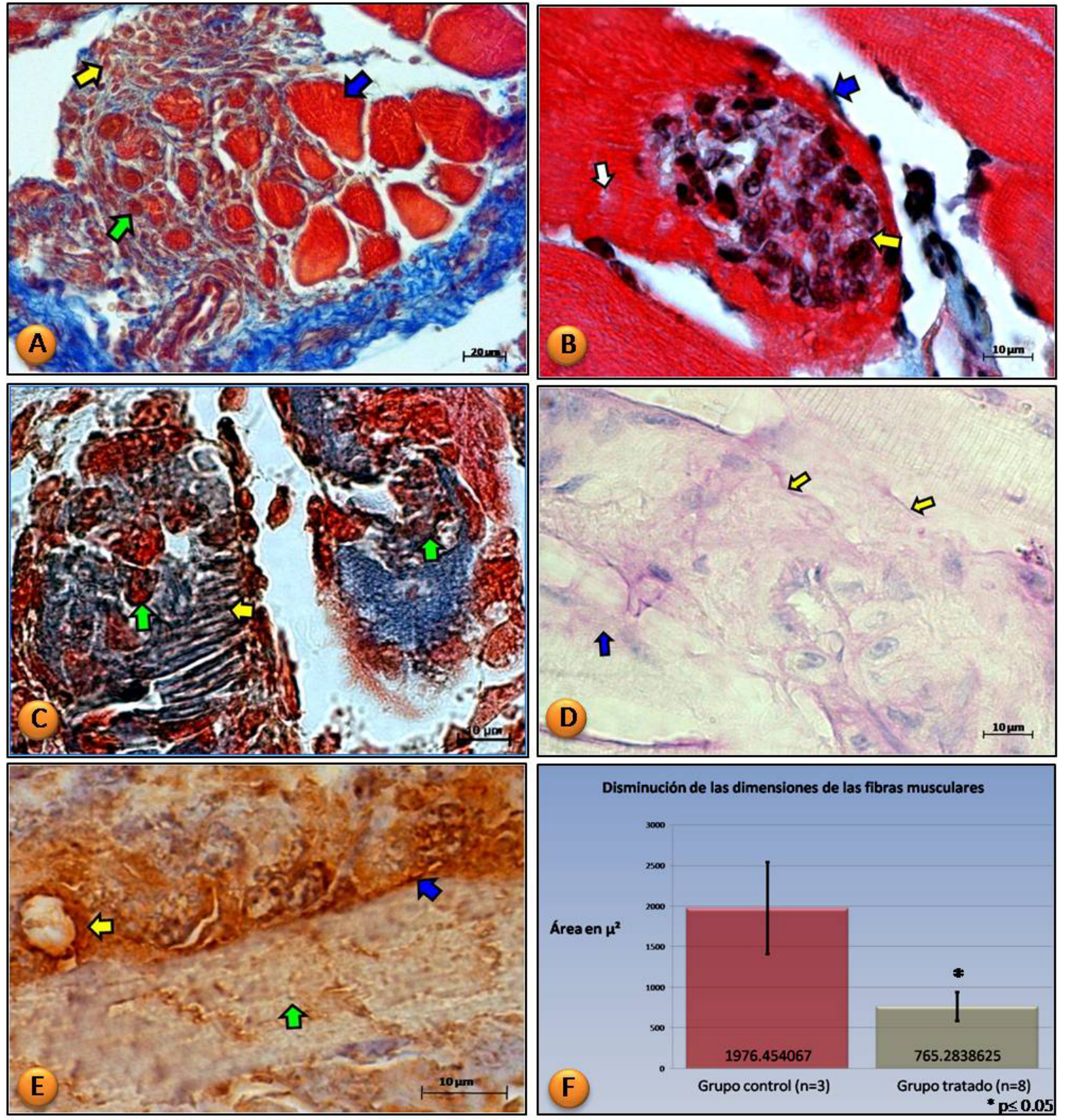

Fig. 1. A) Células TC-1 (flecha amarilla) entre las fibras musculares que muestran disminución en su diámetro (flecha verde). Fibras musculares con diámetro normal (flecha azul). Sitio de implante de las células TC-1. Embebido en parafina, tricrómico de Masson. Micrografía de luz. Barra $20 \mu \mathrm{m}$. B) Masa de células TC-1 en el sarcoplasma de una fibra muscular (flecha amarilla), que muestra espacios en las miofibrillas (flecha blanca) y núcleos en la periferia (flechas azul). Sitio de implante de las células TC-1. Embebido en parafina, tricrómico de Masson. Micrografía de luz. Barra $10 \mu \mathrm{m}$. C) Fibras musculares de color azul en lugar del rojo brillante normal (flecha amarilla), células TC-1 que invaden a las fibras musculares esqueléticas (flechas verdes). Sitio de implante de las células TC-1. Embebido en parafina, tricrómico de Masson. Micrografía de luz. Barra $10 \mu \mathrm{m}$. D) Pérdida de continuidad de la lámina externa que rodea a las fibras musculares (flechas amarillas). Espacio extracelular con material PAS positivo (flecha azul). Sitio de implante de las células TC-1. Embebido en parafina, PAS con diastasa. Micrografía de luz. Barra $10 \mu \mathrm{m}$. E) Células TC-1 con intensa positividad a MMP-9 en el citoplasma (flecha amarilla) y en el espacio (flecha azul) entre las células tumorales y la fibra muscular (flecha verde). Sitio de implante de las células TC-1. Embebido en parafina, inmunohistoquímica. Micrografía de luz. Barra $10 \mu \mathrm{m}$. G) Gráfica que muestra la disminución del diámetro de las fibras musculares en el grupo con el implante de células TC-1. El análisis estadístico muestra que hay diferencia significativa entre el grupo experimental vs el grupo control.* $\mathrm{p} \leq 0.05$. 

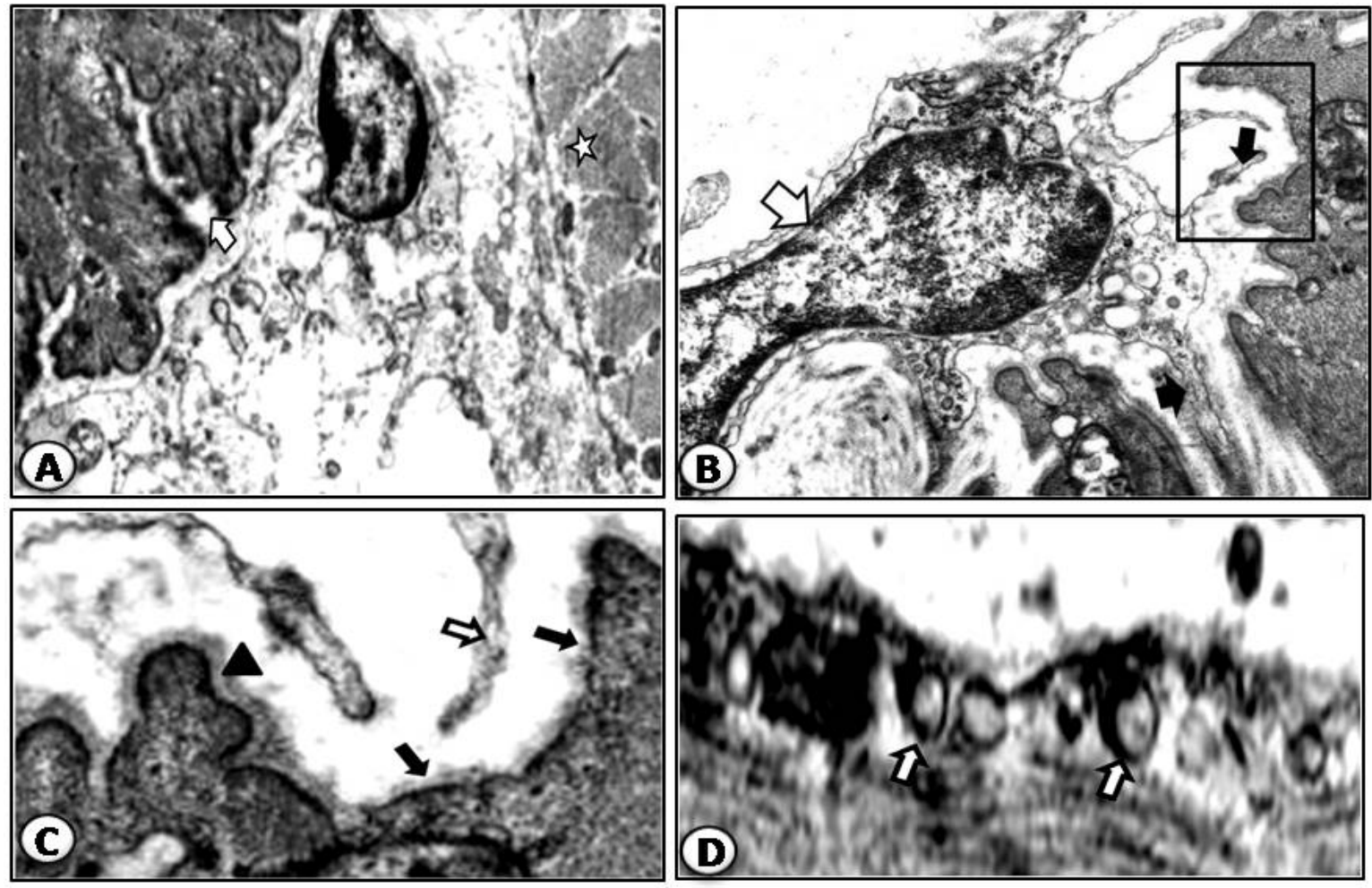

Fig. 2. A) Célula TC-1 entre las fibras musculares que muestran espacios y desorganización de las miofibrillas (flecha blanca). Fibras musculares con disminución en la electrodensidad (estrella). B) Célula TC-1 (flecha blanca) con pseudópodos (flechas negras) en contacto con una porción de una fibra muscular. C) Amplificación del recuadro de la imagen B. Pseudópodos de la célula TC-1 (flecha blanca), interrupciones y variaciones en el grosor de la lámina externa que rodea a las fibras musculares (flechas negras), grosor normal de la lámina externa (cabeza de flecha). D) Porción de una fibra muscular que muestra vesículas subsarcolemales (flechas blancas). Sitio de implante de las células TC-1. Embebido en resinas epóxicas, contraste con acetato de uranilo y citrato de plomo. Micrografía electrónica de trasmisión.

\section{DISCUSIÓN}

En la literatura existen numerosos estudios en los que se utiliza el modelo tumoral murino con células TC-1 descrito por Lin et al. Sin embargo, hasta la fecha no se describe desde el punto de vista morfológico el comportamiento de las células TC-1 en el sitio de implante en ratones C57BL/ 6 , o su interacción con los tejidos circundantes. El presente estudio describe por primera vez la invasión de las fibras musculares por las células TC-1 que logran atravesar la lámina externa y el sarcolema para situarse en el interior del sarcoplasma.

A 10 días post-implante, aún no se observó ninguna tumoración. Sin embargo, en el análisis histológico del sitio del implante de las células tumorales, se identificaron a las células TC-1 que migran e invaden al tejido muscular adyacente. Destaca que en estos sitios las fibras musculares mos- traron un aspecto ondulado, atrofia, separación entre las fibras, y disminución en su diámetro. La inducción de estas alteraciones en las fibras musculares no ha sido descrita previamente para las células TC-1 implantadas. Estos resultados concuerdan con las alteraciones en las fibras musculares reportadas por Brandes et al., y Lamura et al. en un estudio in vivo con células tumorales de leucemia L1210, y en pacientes con carcinoma epidermoide respectivamente.

La disminución del diámetro de las fibras musculares se confirmó con el análisis morfométrico de los diámetros, donde se observó disminución estadística significativa en el grupo experimental comparado con el grupo control. Estos resultados sugieren que las células tumorales TC-1 secretan factores paracrinos que contribuyen a la atrofia de las fibras musculares. 
Estudios in vivo que muestran atrofia de las fibras musculares similar a la observada en nuestro estudio, describen que las células tumorales secretan diversos factores humorales, tales como, el factor inductor de proteólisis (PIF), aislado de pacientes con cáncer y de ratones con células de adenocarcinoma murino (MAC16) (Todorov et al., 1996). Estos factores actúan directamente sobre las fibras musculares y causan atrofia, resultado de un incremento en un $50 \%$ en el catabolismo de proteínas, principalmente de los filamentos de actina y un decremento hasta de un $50 \%$ en las síntesis de proteínas (Belizario et al., 1991; Todorov et al., 1996; Yano et al., 2008). Ambos mecanismos pueden suceder simultáneamente, (Strelkov et al., 1989; Lorite et al., 1997), y dar como resultado la disminución de la masa muscular que se ha relacionado con el estado de caquexia en animales de experimentación y en pacientes con cáncer (Fujiki et al., 1997; Todorov et al., 1999; Cabal-Manzano et al., 2001). En nuestro estudio se observó disminución en el diámetro de las fibras, así como variaciones en la intensidad de la tinción, lo que hace probable que este fenómeno esté ocurriendo en este modelo como parte del proceso destructivo de las células TC-1.

Otro hallazgo en nuestro estudio, fue que se observaron fibras musculares con masas de células tumorales TC-1 en el interior del sarcoplasma. Esta invasión a las fibras musculares se ha asociado a un peor pronóstico en pacientes, $\mathrm{y}$ a un mayor grado de malignidad e invasividad de las células tumorales, como ha sido descrito en estudios tanto en humanos, como en animales de experimentación para tipos celulares tumorales distintos a las células TC-1 (Galasco et al., 1974; Slatkin \& Pearson; Stratton et al.).

Por otra parte, se observó que en los sitios en que las células tumorales invaden a las fibras musculares hay cambio en el patrón de tinción: se tiñen de azul en lugar del rojo brillante característico de las células musculares esqueléticas normales, teñidas con el método tricrómico de Masson. Estos cambios en el patrón tintorial pueden estar relacionados con modificaciones fisicoquímicas intracelulares en las fibras musculares, inducidas por la invasión de las células TC-1.

Al analizar las muestras del sitio del implante con la técnica de PAS con diastasa, se observaron fibras musculares con pérdida de la continuidad de la lámina externa que las rodea en el sitio en que fueron invadidas por las células tumorales. También se observó positividad a la reacción en el citoplasma de las células tumorales que invaden a las fibras musculares, y en células tumorales que infiltran al tejido muscular; así como la presencia de material PAS positivo resistente a la diastasa en el espacio extracelular sin células tumorales. Estos resultados sugieren que las células TC-1 sintetizan y secretan componentes de la matriz extracelular, lo que favorece su migración e invasión a tejidos distantes a su sitio de implante. Este mecanismo ha sido descrito en tipos celulares como carcinoma pulmonar humano (Bolon et al., 1995; Kikkawa et al., 1998) y cáncer de mama (Yee et al., 2007; Theodoro et al., 2007). En la literatura no encontramos reportes que describan este fenómeno para las células TC-1.

Además, se observó positividad a la MMP-9 en el citoplasma de las células tumorales, así como en el espacio entre las células TC-1 y las fibras musculares. Esto sugiere que las células TC- 1 sintetizan y secretan esta enzima proteolítica que degrada a la matriz extracelular y a la lámina externa de las fibras musculares, facilitando así la invasión al músculo esquelético. La síntesis y secreción de esta familia de enzimas está relacionada con resistencia a agentes antineoplásicos, migración y metástasis de las células tumorales a órganos y tejidos distantes a su sitio de origen (Vihinen \& Kähäri, 2002; Visse \& Nagase, 2003).

$\mathrm{Al}$ analizar la ultraestructura de las células TC-1 implantadas, se observaron células íntegras con núcleo eucromático, nucléolo prominente y poco citoplasma con escasos organelos, esto concuerda con lo descrito para las células neoplásicas que presentan alto índice de proliferación sin llevar a cabo alguna función secretora (Lin et al.). Además se observaron células tumorales con características ultraestructurales de la migración celular: núcleos alargados y prolongaciones de la membrana en forma de pseudópodos, esto permite suponer el movimiento activo de las células TC-1 y la invasión a las fibras musculares adyacentes.

En el presente estudio destacó también la observación ultraestructural de interrupciones y variaciones en el grosor de la lámina externa que rodea a las fibras musculares, así como fragmentación del sarcolema y vesículas subsarcolemales asociadas al sitio de fragmentación del sarcolema, estos hallazgos concuerdan con lo descrito por Brandes et al. en un modelo murino con células de leucemia L1210 implantadas.

Así, este es el primer trabajo que demuestra que las células TC-1 son capaces de infiltrar al tejido muscular, destruir la lámina externa y sarcolema que rodea a las fibras musculares, e invadir el interior de las fibras musculares en un periodo de 10 días, cuando aun no hay una tumoración detectable.

Este grado de agresividad e invasividad de las células TC-1, y la presencia de células tumorales localizadas en 
el interior de las fibras musculares, descritas en el presente trabajo, deben ser tomadas en cuenta en estudios en los que se emplea este modelo murino de cáncer para la evaluaciónde la eficacia de inmunoterapia antitumoral. Actualmente en nuestro laboratorio se llevan a cabo estudios para evaluar el posible efecto inhibitorio de agentes antineoplásicos sobre la invasión de las células TC-1 a las fibras musculares.

\section{AGRADECIMIENTOS}

Se agradece a PAICYT 2010 por el apoyo financiero para el presente trabajo, y a CONACYT por la beca No252375. En la ayuda técnica a Nora Frías, Rosa Ma. Leal y Enrique Ramírez.

SOTO-DOMÍNGUEZ, A.; VÁZQUEZ-MORALES, J. I; ROMERO-DÍAZ, V. J.; SANTOYO-PÉREZ, M. E. \& SEPÚLVEDASAAVEDRA, J. Implanted TC-1 cells invade neighboring skeletal muscle fibers in a cancer murine model. Int. J. Morphol., 31(2):520$527,2013$.

SUMMARY: TC-1 cells implanted in C57BL/6 mice are a model for evaluation of anti-tumor immunotherapy. To date there are no reports on the effect of implanted TC-1 cells upon neighboring striated muscle cells. The objective of this work was to evaluate the morphology of the interaction established among the implanted cells and the striated muscle cells. The study was carried out as follows:

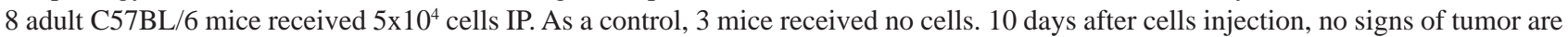
present yet, and the site of cells injection was collected for morphological studies. Samples were processed for light and transmission electron microscopy. Histological sections were stained with H \& E, Masson trichromic method, PAS histochemistry and immunohistochemistry for cytocheratins AE1/AE3, muscle specific actin and for matrix metalloproteinase-9. Cross section diameter of muscle sections was compared among experimental and control groups. The histological evaluation showed groups of tumor cells, infiltrating the spaces among muscle fibers. Muscle fibers showed variations in the cross section diameter as well as in the staining pattern. TC-1 cells were seen very close to muscle cells, invading the lamina externa and sarcolema to finally form groups of cells located within the sarcoplasm. This finding was demonstrated by the specific immunolabel for each kind of cell. Reactivity for metalloproteinase9 was observed within the tumor cells and in the space mediating between the tumor cells and the muscle fiber. At the ultrastructural level, variations of the thickness of lamina externa were observed, as well as interruptions of this structure. Sarcolema also showed fragmentation, and close to these sites a number of subsarcolemmal vesicles were seen. In the vicinity of the muscle fiber, TC- 1 cells formed membrane projections directed towards muscle membrane. Muscle fibers showed a significant diminution of cross section diameter. These findings should be considered, when utilizing this model for evaluating antitumor immunotherapy.

KEY WORDS: TC-1 cells; Intrasarcoplasmic invasion; Cancer murine model.

\section{REFERENCIAS BIBLIOGRÁFICAS}

Albiruni, R.; Chhabra, R.; Hughes, A.; England, P.; Dildey, P. \& McMenemin, R. Metástasis muscular, una presentación muy poco frecuente del cáncer de pulmón de células no pequeñas. MedGenMed., 9(3):20, 2007.

Argilés, J. M.; Busquets, S.; López-Soriano, F. J. \& Figueras, M. Fisiopatología de la caquexia neoplásica. Nutr. Hosp., 21(Supl. 3):4-9, 2006.

Babaï, F. Étude ultrastructurale sur la pathogénie de l'invasion du muscle strié par des tumeurs transplantables. J. Ultrastr. Res., 56(3):287-303, 1976.

Belizario, J. E.; Kartz, M.; Chenker, E. \& Raw, I. Bioactivity of skeletal muscle proteolysis-inducing factors in the plasma protein from cancer patients with weight loss. Br. J. Cancer, 635(5):70510, 1991.

Bolon, I.; Gouyer, V.; Devouassoux, M.; Vandenbunder, B.; Wernert, N.; Moro, D.; et al. Expression of c-ets-1, Collagenase 1, and Urokinase-Type Plasminogen Activator Genes in Lung Carcinomas. Am. J. Pathol., 147(5):1298-310, 1995.
Brandes, D.; Anton, E. \& Schofield, B. Invasion of skeletal and smooth muscle by L1210 Leukemia. Cancer Res., 27(1):215978, 1967.

Cabal-Manzano, R.; Bhargava, P.; Torres-Duarte, A.; Marshall, J.; Bhargava, P. \& Wainer, I. W. Proteolysis-inducing factor is expressed in tumours of patients with gastrointestinal cancers and correlates with weight loss. Br. J. Cancer, 84(12):1599-601, 2001.

Carr, I.; McGinty, F. \& Norris, P. The fine structure of neoplastic invasion of liver, skeletal muscle and lymphatic vessels by the Rd/3 tumour. J. Pathol., 118(2):91-9, 1976.

Ferrandina, G.; Salutari, V.; Testa, A.; Zannoni, G. F.; Petrillo, M. \& Scambia, G. Recurrence in skeletal muscle from squamous cell carcinoma of the uterine cervix: a case report and review of the literature. BMC Cancer, 6:169, 2006.

Fujiki, F.; Mukaida, N.; Hirose, K.; Ishida, H.; Harada, A.; Ohno, S.; et al. Prevention of adenocarcinoma colon 26-induced cachexia by interleukin 10 gene transfer. Cancer Res., 57(1):94-9, 1997.

Gabbert, H.; Gerharz, C. D.; Ramp, U. \& Bohl, J. The nature of host tissue destruction in tumor invasion. Virchows Arch. B Cell Pathol. Incl. Mol. Pathol., 52(6):513-27, 1987. 
Galasko, C. \& Muckle, D. Intrasarcolemmal proliferation of the VX2 carcinoma. Br. J. Cancer, 29(1):59-65, 1974.

Ito, S. \& Karnowsky, M. Formaldehyde-glutaraldehyde fixative containing trinitro compounds. J. Cell. Biol., 39:168-9, 1968.

Kang, T. H.; Mao, C. P.; He, L.; Tsai, Y. C.; Liu, K.; La, V.; et al. Tumor-targeted delivery of IL-2 by NKG2D leads to accumulation of antigen-specific CD8+ T cells in the tumor loci and enhanced anti-tumor effects. PLoS One, 7(4):e35141, 2012.

Kikkawa, Y.; Sanzen, N. \& Sekiguchi, K. Isolation and Characterization of Laminin-10/11 Secreted by Human Lung Carcinoma Cells.Laminin-10/11 Mediates Cell Adhesion Through Integrin a3b1. J. Biol. Chem., 273(25):15854-9, 1998.

Lamura, A.; Finol, H.; Garriga, E.; Muller, B. \& Lamura, G. Estudio clínico, histopatológico y ultraestructural del músculo de la lengua en pacientes con carcinoma epidermoide. Act. Odont. Venez., 41(1):36-43, 2003.

Lin, K.; Guarnieri, F. G.; Staveley-O'Carroll, K. F.; Levitsky, H. I.; August, J. T.; Pardoll, D. M.; et al. Treatment of established tumors with a novel vaccine that enhances major histocompatibility class II presentation of tumor antigen. Cancer Res., 56(1):21-6, 1996.

Lorite, M. J.; Cariuk, P. \& Tisdale, M. J. Induction of muscle protein degradation by a tumor factor. Br. J. Cancer, 76(8):1035-40, 1997.

Luft, J. Improvements in epoxy resin embedding methods. J. Biophys. Biochem. Cytol., 9:409-14, 1961.

Luo, C.; Jiang, Y.; Liu, Y. \& Li, X. Experimental study on mechanism and rarity of metastasis in skeletal muscle. Chin. Med. J. (Engl.), 115(11):1645-9, 2002.

Mathis, S.; Fromont-Hankard, G.; du Boisguéheneuc, F.; Godenèche, G.; Mahieu, F.; Balaboi, I. et al. Les métastases des muscles striés. Rev. Neur., 166(3):295-304, 2010.

Slatkin, D. \& Pearson, J. Intramyofiber metastases in skeletal muscle. Hum. Pathol., 7(3):347-9, 1976.

Smahel, M.; Síma, P.; Ludvíková, V.; Marinov, I.; Pokorná, D. \& Vonka, V. Immunization with modified HPV16 E7 genes against mouse oncogenic TC-1 cells sublines with downregulated expression of MHC class I molecules. Vaccine, 21(11-12):1125-36, 2003.

Sridhar, K.; Rao, R. \& Kunhardt, B. Skeletal muscle metastases from lung cancer. Cancer, 59(8):1530-4, 1987.

Stratton, B.; Askin, F. B. \& Kissane, J. M. Intramyofiber skeletal muscle invasion in Ewing's sarcoma of bone: clinicopathologic observations from the intergroup Ewing's sarcoma study. Am. J. Pediatr. Hematol. Oncol., 4(2):231-5, 1982.

Strelkov, A. B.; Fields, A. L. \& Baracos, V. E. Effect of systemic inhibition of prostaglandin production on protein metabolism in tumor-bearing rats. Am. J. Physiol., 275(2 Pt. 1):C261-9, 1989.

Theodoro, T. R.; de Matos, L. L.; Sant Annay, A. V.; Fonseca, F. L.; Semedo, P.; Martins, L. C.; et al. Heparanase Expression in
Circulating Lymphocytes of Breast Cancer Patients Depends on the Presence of the Primary Tumor and/or Systemic Metastasis. Neoplasia, 9(6):504-10, 2007.

Todorov, P.; Cariuk, P.; McDevitt, T.; Coles, B.; Fearon, K. C. \& Tisdale, M. J. Characterization of a cancer cachectic factor. Nature, 379(6567):739-42, 1996.

Todorov, P. T.; Field W. N. \& Tisdale, M.. J. Role of a proteolysisinducing factor (PIF) in cachexia induced by a human melanoma (G361). Br. J. Cancer, 80(11):1734-7, 1999.

Tuve, S.; Chen, B. M.; Liu, Y.; Cheng, T. L.; Touré, P.; Sow, P. S.; et al. Combination of tumor site-located CTL-associated antigen-4 blockade and systemic regulatory T-cell depletion induces tumor destructive immune responses. Cancer Res., 67(12):5929-39, 2007.

Ueyama, H.; Kumamoto, T.; Johno, M.; Mita S. \& Tsuda, T. Localized muscle wasting as an inicial symptom of skeletal muscle lymphoma. J. Neurobiol. Sci., 154(1):113-5, 1998.

Venable, J. H. \& Coggeshall, R. A simplified lead citrate stain for use in electron microscopy. J. Cell. Biol., 25:407-8, 1965.

Vihinen P. \& Kähäri, V. M. Matrix metalloproteinases in cancer: prognostic markers and therapeutic targets. Int. J. Cancer, 99(2):157-66, 2002.

Visse, R. \& Nagase, H. Matrix metalloproteinases and tissue inhibitors of metalloproteinase: structure, function and biochemistry. Circ. Res., 92(8):827-39, 2003.

Watson, M. L. Staining of tissue sections for electron microscopy with heavy metals. II. Applications of solutions containing lead and borium. J. Biophys. Biochem. Cytol., 4(6):727-30, 1958.

Yano, C. L.; Ventrucci, G.; Field, W. N.; Tisdale, M. J. \& GomesMarcodes, M. C. Metabolic and morphological alterations induced by proteolysis-inducing factor from Walker tumour-bearing rats in C2C12 myotubes. BMC Cancer, 8:24, 2008.

Yee, A. J.; Akens, M.; Yang, B. L.; Finkelstein, J.; Zheng, P. S.; Deng, Z.; et al. The effect of versican G3 domain on local breast cancer invasiveness and bony metastasis. Breast Cancer Res., 9(4):R47, 2007.

\section{Correspondence to:}

Dr. Julio Sepúlveda-Saavedra

Facultad de Medicina

Universidad Autónoma de Nuevo León

Departamento de Histología, AP 1563

Monterrey, N.L. 64400

MÉXICO

\section{Email: jusesaa@netscape.net}

Recibido : 07-12-2012

Aceptado: 26-02-2013 